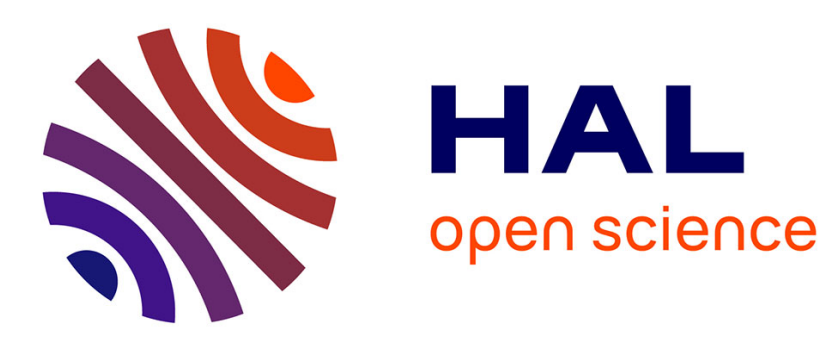

\title{
Production planning under a Working Time Accounts scheme
}

\author{
Amaia Lusa, Albert Corominas, Jordi Olivella, Rafael Pastor
}

\section{To cite this version:}

Amaia Lusa, Albert Corominas, Jordi Olivella, Rafael Pastor. Production planning under a Working Time Accounts scheme. International Journal of Production Research, 2009, 47 (13), pp.3435-3451. 10.1080/00207540802356762 . hal-00513045

\section{HAL Id: hal-00513045 \\ https://hal.science/hal-00513045}

Submitted on 1 Sep 2010

HAL is a multi-disciplinary open access archive for the deposit and dissemination of scientific research documents, whether they are published or not. The documents may come from teaching and research institutions in France or abroad, or from public or private research centers.
L'archive ouverte pluridisciplinaire HAL, est destinée au dépôt et à la diffusion de documents scientifiques de niveau recherche, publiés ou non, émanant des établissements d'enseignement et de recherche français ou étrangers, des laboratoires publics ou privés. 


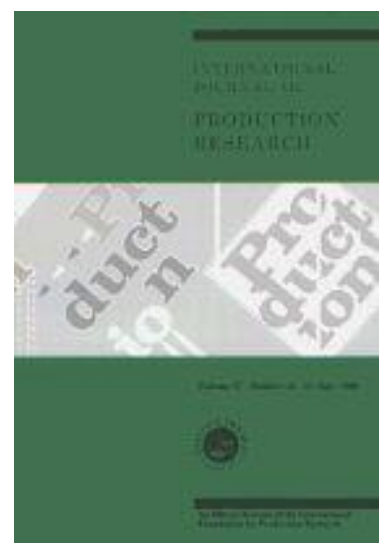

Production planning under a Working Time Accounts scheme

\begin{tabular}{|r|l|}
\hline Journal: & International Journal of Production Research \\
\hline Manuscript ID: & TPRS-2008-IJPR-0558 \\
\hline Manuscript Type: & Original Manuscript \\
\hline Date Submitted by the \\
Author: & $14-J u l-2008$ \\
\hline Complete List of Authors: & $\begin{array}{l}\text { Lusa, Amaia; Universitat Politècnica de Catalunya } \\
\text { Corominas, Albert; Universitat Politècnica de Catalunya (UPC) } \\
\text { Olivella, Jordi; Universitat Politècnica de Catalunya (UPC), } \\
\text { Management Department } \\
\text { Pastor, Rafael; Universitat Politècnica de Catalunya (UPC) }\end{array}$ \\
\hline Keywords: & PRODUCTION PLANNING, WORK MEASUREMENT \\
\hline Keywords (user): & Personnel Managemernt, MILB \\
\hline \multicolumn{2}{|c}{} \\
\hline
\end{tabular}

\section{S) ScholaroNE \\ Manuscript Central}




\title{
Production planning under a Working Time Accounts scheme
}

\author{
Amaia Lusa"; Albert Corominas; Jordi Olivella; Rafael Pastor \\ Institute of Industrial and Control Engineering / Management Department \\ Universitat Politècnica de Catalunya (UPC); Barcelona; Spain
}

Amaia Lusa: Avda. Diagonal 647, p11, 08028 Barcelona (Spain). Tlf.: +34934011705.

Fax:+34934016605. E-mail:amaia.lusa@upc.edu

Albert Corominas: Avda. Diagonal 647, p11, 08028 Barcelona (Spain). Tlf.: +34934011615.

Fax:+34934016605. E-mail: albert.corominas@upc.edu

Jordi Olivella: Avda. del canal olímpic, S/N, 08860 Castelldefels (Spain). Tlf.: +34934137236.

Fax:+34934016605. E-mail:jorge.olivella@upc.edu

Rafael Pastor: Avda. Diagonal 647, p11, 08028 Barcelona (Spain). Tlf.: +34934011701.

Fax:+34934016605. E-mail: rafael.pastor@upc.edu

\begin{abstract}
Working Time Accounts (WTA) provide flexibility to the company to adjust the capacity to the demand by planning, for each period and each worker, an appropriate number of working hours. Under this scheme, every worker has a balance that can be positive (the company owes hours to the worker), zero or negative (the worker owes hours to the company). Credit (or debit) hours are compensated by working less (or more) hours than the reference value in the subsequent periods. This scheme is especially useful for companies dealing with demand fluctuations, because WTA balances can take any value, provided that these belong to a given bounded interval. Other conditions that affect the number and distribution of working hours may be established either in law or in the WTA agreement. This paper proposes a new mathematical model for planning production, inventory levels, working time and temporary closures in a manufacturing company operating under a standard WTA scheme. The results of
\end{abstract}

\footnotetext{
*Corresponding author. E-mail: amaia.lusa@upc.edu
} 
the computational study show that the model is an appropriate tool not only for planning but also for helping in the bargaining process (different WTA scheme configurations could be evaluated with the model).

Keywords: working time accounts, production planning, personnel management, MILP

\section{Introduction}

Matching production and demand is a central issue in every production system, which in manufacturing has been traditionally achieved by means of inventory. However, the trend to lean production leads to low inventory policies and, therefore, to systems with flexible capacity. Flexible human resources are often the main means to get flexible capacity.

In this context, three kinds of human resources flexibility practices can be considered: functional, external and internal. Functional flexibility or cross-training allows workers to participate at different points of a process and at different processes; the possibility of reallocating workers from one task to another is a source of flexibility. External flexibility implies changes in the number of employees. Staff reduction, with temporary measures or through firing, and new hired workers, permit a continuous adaptation of capacity to the required level. However hiring and firing schemes, besides being undesirable from many points of view, cannot be applied to meet short-term requirements when a long initial training period is necessary and when accumulated knowledge and experience are an inherent and important part of the work. Finally, internal flexibility is derived from using shorter or longer working time according to the capacity requirements. This flexibility is usually very advantageous from the company point of view: demand can be met without having to hire and fire employees and minimising the use of temporary personnel; overtime is no longer needed or significantly reduced; and there is no need of having high inventory levels. However, doing irregular hours may affect workers private life and, hence, is not easily accepted if there is not an adequate compensation in exchange of the flexibility provided by workers. This compensation, which has to be agreed by company and workers, can be a reduction in the total number of working hours, an economic incentive or, in some cases, a guarantee of keeping the job even in low demand periods.

There are different modalities of flexibly managing working time. Annualised hours (i.e. distributing irregularly throughout the year a given amount of hours) are a modality adequate to meet a foreseeable seasonal demand (Hung, 1999; Corominas, Lusa and Pastor, 2002 and 2004; Lusa, Corominas and Pastor, 2008). Under a working time account (WTA) scheme every employee has, at any moment, a balance of worked hours 
that must belong to an interval defined by a negative lower bound and a positive upper bound (e.g. -200 and +300 , respectively). A positive (credit) balance, expresses that the company owes hours to the worker; a negative (debit) one, instead, means that the worker owes hours to the company. Every period, the number of hours worked above a reference value (e.g., 40 hours a week) is added to the balance, whilst the number of hours worked below the reference value is subtracted from the balance. This way, the positive (negative) balances are compensated in the future working below (above) the reference value.

Of course, to avoid a significant worsening in workers working conditions (due to having to do irregular hours) the distribution of working time must comply with some bounds and conditions either set in law or in the agreement between the company and the workers. Alternatively or concurrently workers may be compensated for by commitments on employment security (Seifert and Massa-Wirth, 2005) or by the possibility to take the days in lieu according to their interest (Berg et al., 2004).

WTA firstly appeared to supply flexibility to the workers (Owen, 1977), provided that this flexibility did not harm the activity of the company. When a WTA scheme is used according to the needs of the company (production requirements) - as it is considered in this paper - they are a source of internal flexibility. This scheme was initially implemented in Germany, by the automotive sector, and developed afterwards in other industries and countries (Lehndorff, 1999). Indeed, different flexibility clauses have been used in German automotive factories for more than 20 years. A 1984 agreement between IG Metall and the metalworking employers' association (Gesamtmetall) about the establishment of WTA was a major boost to these practices (Lehndorff, 1999). After this agreement automotive companies like Volkswagen, Opel, DaimlerChrysler and BMW, adopted working time flexibility clauses (Lehndorff, 2000). There is a large variety in these agreements, even within the same company, but all of them contain the use of WTA. The negotiation at company or plant level leads to the concrete conditions of each case (Haipeter and Lehndorff, 2005).

WTA have been also adopted in factories of the rest of Europe (Corominas, Olivella and Pastor, 2006). In France, Renault adopted this scheme by means of collective agreement in January 1996. Peugeot Citroen introduced annual accounted working time and working time accounts in March 1999. In this case the number of hours that workers can owe to the company at the end of the year was limited to the equivalent of five working days. In Spain, several companies, such as Renault, Opel, Seat and Sony factories, have adopted different flexibility schemes from the late nineties. This also happened in Austria, where the BMW plant in Steyr has operated flexible working time schemes since May 1999, and in the United Kingdom, in the Oxford factory of Mini (BMW Group). In Italy WTA were adopted by the private metal industry from June 1999. In addition, all the numerous cases in which overtime is compensated by free time can be 
also assimilated to a WTA scheme, although the account is not explicitly defined. Of course, despite having their origin in the automotive industry, WTA can be applied to other manufacturing activities and to services as well (Corominas, Olivella and Pastor, 2006; Pastor and Olivella, 2008).

When a WTA scheme is adopted there is the need of planning production and working time with a sufficiently long horizon; otherwise, the company would not exploit all the flexibility provided by this kind of scheme. Furthermore, planning production and working time under WTA and considering a particular set of conditions (e.g., bounds of the WTA balance) gives quantitative information that can be used in the bargaining process that is always required before adopting such a scheme. Indeed, evaluating different scenarios (by means of a planning) could help company and workers reaching an agreement satisfactory for both.

The planning problem in manufacturing under a WTA scheme has some characteristics that make it very different from the classic workload coverage problem in services. On one hand, the possibility of using inventories; on the other hand, usually manufacturing processes require the simultaneous presence of a group of workers, limiting thus the use of individual timetables.

To our knowledge, the production planning problem under a WTA scheme has not yet been studied in the literature. This paper proposes a new mathematical model for planning production, inventory levels, working time and temporary closures in a manufacturing company operating under a standard WTA scheme. The main difference with the existing WTA planning model for services (Corominas, Olivella and Pastor, 2006; Pastor and Olivella, 2008) is that in services industries the moment of meeting the demand coincides with the moment of doing the work and thus what have to be determined are basically the days and hours of work of each worker, while in the model proposed here we determine the weekly working hours of the team, the volume of production per product and the inventory levels at each period.

The paper is organized as follows: in section 2 the planning problem is described; in section 3 a mixed integer linear programming model is introduced; section 4 contains the results of a computational study; finally, section 5 contains the main conclusions and proposes further research lines.

\section{Production planning problem under a WTA scheme}

Planning under a WTA scheme, given demand forecasts, consists in determining the number of working hours for a human team involved in a multi-product manufacturing process and the units of products to be produced, for every period (e.g. week) of the 
planning horizon. We assume that all team members must carry out the same working hours, that is to say, the process requires the simultaneous intervention of all team members.

The constraints of the planning problem depend on the specific characteristics of each case. For the purposes of the paper and in order to build a basic model, the most common features of WTA schemes are considered. For example, all the known WTA schemes establish a lower and an upper bound on the balance of the WTA. Moreover, adopting a WTA scheme does not prevent of using overtime, as this provides even more flexibility for adapting capacity to requirements.

It is supposed that all workers take their holidays at the same time and that in those weeks the production process is interrupted. The possibility of temporary closures has also to be considered. Notwithstanding, demand is served all periods of the horizon, provided that there is enough inventory to do so. It is also assumed that the demand that cannot be served is lost.

For every working week it is assumed that there is a reference value $(h)$, a lower bound $\left(h^{-}\right)$to avoid extremely short working hours, an upper bound $\left(h^{+}\right)$on ordinary hours, and a higher upper bound that can be only reached by means of overtime $\left(h^{++}\right)$. As it can be seen in Figure 1, the hours worked below $h$ are subtracted from the WTA, the hours above $h$ and up to $h^{+}$are added to the WTA, and the hours worked between $h^{+}$and $h^{++}$ are considered and paid as overtime and are not computed in the WTA.

For each worker, the WTA balance should be kept between a lower and an upper bound ( $S^{-}$and $S^{+}$, respectively). In a given period, all workers have to do the same working hours. However, due to differences in seniority, sick leaves, etc., not all of them have the same balance at the beginning of the planning horizon and, therefore, generally speaking, their balances can be different in any period. This fact can give raise to a variety of situations for which adequate rules have to be defined. For example, it could happen that, under a high production requirement, the number of working hours would have to be low just to avoid that a worker who had reached the upper bound exceeded it. It could also take place the opposite situation, under a low production requirement, if some workers had reached the lower bound. To deal with these situations and, in general, provide more flexibility to the WTA scheme, it is permitted that a worker works above (below) the reference value when he or she has reached the upper (lower) bound of the WTA balance. In the case of having reached the upper bound $\left(S^{+}\right)$, the hours worked above the reference value are computed and paid (at a special price, inferior than that of overtime) as overaccount hours, whose total value is also upper bounded. In the case of having reached the lower bound $\left(S^{-}\right)$, the hours worked below the reference value are considered as underaccount, which means that the worker does not have to make them up (i.e., are forgiven hours). These conditions are also depicted 
in Figure 1, where some variables are also included (see section 3 for variable definitions). An example of this schema is the collective agreement of Volkswagen in Germany (Dribbusch, 2004), which establishes that, while WTA upper bound - 400 hours- is not reached, weekly worked hours between 35 and 40 are accounted in the WTA and hours over 40 are paid as overtime, and when WTA upper bound is reached, all hours over 35 are paid as overtime.

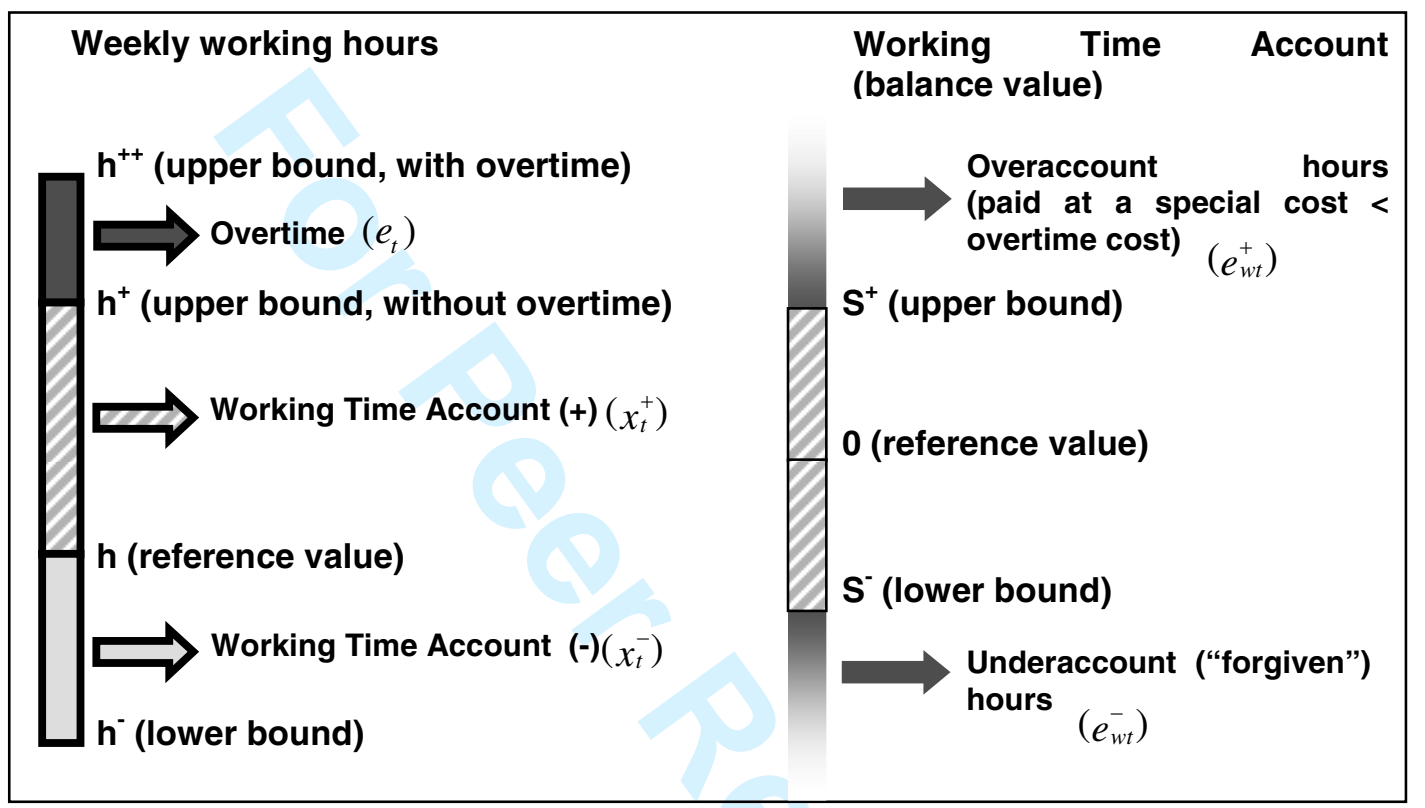

Figure 1. Conditions of the WTA scheme

The characteristics of the planning problem here considered are summarized below:

- There is a requirement for every product and every week of the planning horizon and delays are not permitted (there is a cost when product requirements are not met).

- For each product, an hourly productivity is assumed to be known.

- Inventories at the beginning of the planning horizon and inventory holding costs are known.

- In any given period, all workers have to do the same working hours (the process requires the simultaneous intervention of all workers).

- All workers take their holidays simultaneously and, in those weeks, production is interrupted but demand to be served still exists.

- The balances of the WTA at the beginning of the planning horizon may not be the same for all workers, but they are known. 
- Overtime is permitted, and the total number of overtime in the planning horizon is upper bounded.

- In every working week, the number of ordinary working hours must be kept between a lower and an upper bound $\left(h, h^{+}\right)$. Overtime must be kept between the maximum number of ordinary hours $\left(h^{+}\right)$and the upper bound considering overtime $\left(h^{++}\right)$.

- For every worker and every week, the WTA balance must be kept between a lower and an upper bound $\left(S^{-}, S^{+}\right)$.

- The hours worked above (below) the reference value are added (subtracted) to the WTA balance. If the worker has reached the upper (lower) bound of the WTA balance, the hours worked above (below) the reference value are considered as overaccount (underaccount) and paid (forgiven) to the worker. There is an upper bound on the total number of overtime plus overaccount hours in the planning horizon.

- There is a lower and an upper bound on the global WTA balance (sum of workers WTA balances) at the end of the planning horizon, as a precautionary measure to take into account the requirements of later periods.

The aim is to solve the planning problem presented above in such a way that an objective function is optimised. The objective function that seems more appropriate for this case is to minimise the sum of the cost (including production, inventory, lost demand, overtime and overaccount), the penalty for the underaccount (forgiven) hours and the penalty for the final global balance (to penalize solutions with positive balances, negative balances or both).

The planning problem has been modeled by means of a mixed integer linear programming model, which is described in the following section.

\section{Planning model}

As already mentioned, due to differences in the length of service, sick leaves and other reasons, usually the initial situation (WTA balance) will not be the same for all workers. Thus, even tough working hours are the same for all workers, balances must be individualized to guarantee that constraints affecting the working time account are accomplished for every worker. 
We make use of the following data, parameters and variables. It is considered that the data are all those values out of company's control, whilst the parameters are those that define the characteristics of the WTA scheme and that, therefore, have to be agreed between the company and the workers.

Data:

$T \quad$ number of periods of the planning horizon $(\mathrm{t}=1, \ldots, T)$.

$E \quad$ ordered set of numbers of production periods (excluding from the planning horizon those periods in which workers are on holidays).

$P \quad$ set of products.

$I_{p 0} \quad$ inventory of product $p$ at the beginning of the planning horizon $(\forall p \in P)$.

$d_{p t} \quad$ forecasted demand of product $p$ in period $t(\forall p \in P ; t=1, \ldots, T)$.

$\rho_{p} \quad$ productivity (in units/hour) for product $p(\forall p \in P)$.

W $\quad$ set of workers.

$s_{w 0} \quad$ balance of the WTA of worker $w(\forall w \in W)$ at the beginning of the planning horizon, which may be negative, zero or positive.

$c p_{p} \quad$ unit variable production cost for product $p(\forall p \in P)$, excluding personnel costs.

$c i_{p} \quad$ inventory holding cost, for a period, of one unit of product $p(\forall p \in P)$.

$c r_{p} \quad$ cost of one unit of lost demand of product $p(\forall p \in P)$.

Parameters:

$S^{-}, S^{+} \quad$ lower and upper bound, respectively, of the WTA balance (for every week and every worker); notice that $S \leq 0$.

$h \quad$ normal or reference number of hours, for every worker and every period.

$h^{-}, h^{+} \quad$ lower and upper bounds, respectively, for the number of ordinary working hours, for every worker and every period.

$h^{++} \quad$ upper bound for the number of working hours, for every worker and every period.

$u_{w} \quad$ upper bound, for the duration of the planning horizon, on the number of overtime hours for worker $w(\forall w \in W)$.

$\hat{u}_{w} \quad$ upper bound, for the duration of the planning horizon, on the number of overtime hours plus the number of overaccount hours for worker $w$ $(\forall w \in W)$. Notice that another possibility would be to define an upper bound 
for the overtime and an upper bound for the overaccount (instead of overtime+overaccount).

$w t a^{-}, w t a^{+}$lower and upper bound on the global WTA balance (i.e., the sum of the WTA balances for all workers) at the end of the planning horizon.

$\alpha \quad$ cost of one hour of overtime (per worker).

$\beta \quad$ cost of one hour of overaccount time (per worker). Logically, we assume that $\beta<\alpha$.

$\lambda_{1} \quad$ penalty for one underaccount hour.

$\lambda_{2} \quad$ weight for the positive global WTA balance at the end of the planning horizon.

$\lambda_{3} \quad$ weight for the negative global WTA balance at the end of the planning horizon.

Variables:

$q_{p t} \geq 0 \quad$ quantity of product $p$ produced in period $t(\forall p \in P ; \forall t \in E)$.

$I_{p t} \geq 0 \quad$ inventory of product $p$ at the end of period $t(\forall p \in P ; t=1, \ldots, T)$.

$r_{p t} \geq 0 \quad$ lost demand of product $p$ in the period $t(\forall p \in P ; t=1, \ldots, T)$.

$x_{t}^{-}, x_{t}^{+} \geq 0$ working hours below and above, respectively, the reference value $h$, in the period $t(\forall t \in E)$. The variables $x_{t}^{+}$correspond to the regular hours, that is, those not considered as overtime. Note that since the number of working hours, in each period, is the same for all workers, it is not necessary to individualize these variables.

$e_{t} \geq 0 \quad$ overtime hours in period $t(\forall t \in E)$. Again, it is not necessary no individualize these variables (the overtime is the same for each worker).

$e_{w t}^{+} \geq 0 \quad$ overaccount hours of worker $w$ in period $t(\forall w \in W, \forall t \in E)$.

$e_{w t}^{-} \geq 0 \quad$ underaccount hours of worker $w$ in period $t(\forall w \in W, \forall t \in E)$.

$c l_{t} \in\{0,1\}$ takes value 1 if in week $t(\forall t \in E)$ the company closes (for example due to low product requirements) and value 0 otherwise.

$y_{t} \in\{0,1\}$ auxiliary variable to guarantee that, in each period, at least one of the variables $x_{t}^{-}$and $x_{t}^{+}$is equal to zero $(\forall t \in E)$.

$s_{w t} \quad$ WTA balance of worker $w$ in the period $t(\forall w \in W, \forall t \in E) ; s_{w t}$ may be negative (which indicates that worker $w$ owes hours to the company), zero or positive (which indicates that the company owes hours to the worker). 
$f^{+}, f^{-} \geq 0$ positive and negative global balance (sum of the WTA balances for all workers), respectively, at the end of the planning horizon.

Model:

$$
\begin{aligned}
& {[M I N] z=\sum_{t \in E} \sum_{p \in P} c p_{p} q_{p t}+\sum_{t=1}^{T} \sum_{p \in P}\left(c i_{p} I_{p t}+c r_{p} r_{p t}\right)+} \\
& \sum_{t \in E} \sum_{w \in W}\left(\alpha e_{t}+\left(\beta-\frac{t}{K \cdot|E|}\right) e_{w t}^{+}+\lambda_{1} e_{w t}^{-}\right)+\lambda_{2} f^{+}+\lambda_{3} f^{-} \\
& q_{p t}+I_{p, t-1}+r_{p t}=d_{p t}+I_{p t} \quad \forall p \in P ; \forall t \in E \\
& I_{p, t-1}+r_{p t}=d_{p t}+I_{p t} \quad \forall p \in P ; \forall t \notin E \\
& \sum_{p \in P} \frac{q_{p t}}{\rho_{p}} \leq h+x_{t}^{+}-x_{t}^{-}+e_{t} \quad \forall t \in E \\
& s_{w 1}=s_{w 0}+\left(x_{1}^{+}-e_{w 1}^{+}\right)-\left(x_{1}^{-}-e_{w 1}^{-}\right) \quad \forall w \in W \\
& s_{w t}=s_{w j}+\left(x_{t}^{+}-e_{w t}^{+}\right)-\left(x_{t}^{-}-e_{w t}^{-}\right) \quad \forall w \in W ; \forall t \in E-\{1\} ; j=\max _{k \in E \mid k<t}(k) \\
& \sum_{t \in E} e_{t} \leq u_{w} \quad \forall w \in W \\
& \sum_{t \in E}\left(e_{t}+e_{w t}^{+}\right) \leq \hat{u}_{w} \quad \forall w \in W \\
& \sum_{w \in W} s_{w T}=f^{+}-f^{-} \\
& 0 \leq f^{+} \leq w t a^{+} \\
& 0 \leq f^{-} \leq w t a^{-} \\
& h_{c l_{t}} \leq x_{t}^{-} \leq h-h^{-}\left(1-c l_{t}\right) \quad \forall t \in E \\
& 0 \leq x_{t}^{+} \leq\left(h^{+}-h\right) y_{t} \quad \forall t \in E \\
& x_{t}^{-} \leq\left(h-h^{-}\right)\left(1-y_{t}\right) \quad \forall t \in E \\
& 0 \leq e_{t} \leq h^{++}-h^{+} \quad \forall t \in E \\
& S^{-} \leq s_{w t} \leq S^{+} \quad \forall w \in W ; \forall t \in E \\
& 0 \leq e_{w t}^{+} \leq x_{t}^{+} \quad \forall w \in W ; \forall t \in E
\end{aligned}
$$




$$
\begin{aligned}
& 0 \leq e_{w t}^{-} \leq x_{t}^{-} \\
& c l_{t}, y_{t} \in\{0,1\} \\
& q_{p t}, I_{p t}, r_{p t} \geq 0
\end{aligned} \quad \forall w \in W ; \forall t \in E
$$

Equation (1) is the objective function that includes the costs of production, inventory, unsatisfied requirements, overtime and overaccount time. Penalties on underaccount, positive and negative final global balances are also included. Note that the cost of an overaccount hour in period $t$, which is equal to $\beta$, has been replaced by $\left(\beta-\frac{t}{K \cdot|E|}\right)$ in the objective function (where $|E|$ is the number of production periods and $K$ a big enough positive constant-equal to 100 in the computational experiments). The effect of this change in the coefficients is that the cost of overaccount hours is considered the (slightly) more expensive the closer they fall to the start of the planning horizon, thus preventing hours to be considered as overaccount (instead of adding them to the WTA balance, see equations (5) and (6)) before the upperbound of the WTA is reached. Note that without this modification overaccount hours belonging to different periods would be equivalent regardless of their allocation in the planning horizon. A similar thing is proposed by Dellaert and Jeunet (2003) under the consideration that, in a rolling schedule the costs occurring close to the beginning of the planning horizon are reliable, whereas the other costs are all 'future' costs, which may be subject to change. Giving a different weight to costs belonging to periods close to the beginning of the planning horizon and costs belonging to future periods avoids or reduces the first ones.

Equations (2) and (3) are the production, inventory, lost demand and demand balances; (4) expresses that the number of working hours required for the production (i.e., the sum, for each product, of the number of units to produce divided by the number of units that are produced in one hour, which gives the number of needed production hours) must not be greater than the available hours (i.e., overtime plus the number of ordinary working hours, which is equal to the reference value plus the number of hours above the reference value minus the number of hours below the reference value); (5) and (6) express, for each group of workers and for each working period, the WTA balance (note that, in (6), $j$ is the last working week before $t$ ); (7) and (8) impose, for each group of workers, the upper bounds, for the duration of the planning horizon, on the number of overtime hours and the number of overtime hours plus the number of overaccount hours; (9) computes the global WTA balance, as the sum of the WTA balances for all workers, at the end of the planning horizon; (10) and (11) impose the lower and upper bounds, on the positive and negative global WTA balance, respectively, at the end of the planning horizon; (12) imposes that if variable $c l_{t}$ takes value 1 , then the number of hours below the reference value, $h$, is equal to $h$, which is equivalent to say that the 
number of working hours is equal to 0 , meaning that the company would close during that period (which may be convenient if the demand is very low). If, on the contrary, $c l_{t}$ is equal to 0 , then the upper bound on the number of hours below the reference value, $h$, is imposed. Equations (13) and (14) impose that, in each period, at least one of the variables $x_{t}^{-}$and $x_{t}^{+}$is equal to zero. Equations (15) to (18) impose the lower and upper bounds on the working hours below and above the reference value, the overtime hours, the WTA balance, the overaccount hours and the underaccount hours, respectively. Finally, (19) imposes the binary character of the $c l_{t}$ and $y_{t}$ variables and (20) imposes the non-negative character of the remaining variables.

Note that, when the number of workers is high, there is a way of reducing the number of variables and constraints of the model. If two or more workers have the same WTA balance at the beginning of the planning horizon, they will have, in the solution of the model, the same WTA balance at all periods, since the number of working hours, at each period, is assumed to be the same for all workers. Hence these workers can be grouped together and it is not necessary to declare the WTA variables for each one, but for the group. This way of grouping workers according to their initial WTA balance would allow us reducing the number of variables and constraints and, hence, dealing with problems entailing a large number of workers.

Some companies work 24 hours a day and 5 days a week. For these companies, it is not possible to extend working hours unless Saturday is considered as a working day. Furthermore, production would not start on a Saturday unless a minimum number of hours $\left(h_{s}\right)$ were required. Adapting the model to this kind of situation is straightforward, as it is enough to change equation (13) as follows: $h_{s} y_{t} \leq x_{t}^{+} \leq\left(h^{+}-h\right) y_{t}, \forall t \in E$.

\section{Computational study}

Two computational experiments were performed in order to evaluate the performance of the model. The set of data and parameters used for the computational study was designed to cover a number of representative real cases specific of the problem. With this aim collective agreements of Volkswagen, Opel, DaimlerChrysler and BMW in Germany, Renault in France and Renault, Opel and Seat in Spain were analyzed. This allowed us to test the effectiveness of the model and its sensitivity in relation to the data and parameters that define an instance.

\subsection{Experiment 1}

The data and parameters took the following values: 
- $T=52$ weeks

- $E=\{1, \ldots, 15\} \cup\{20, \ldots, 52\}$.

- One product, with an initial inventory of 40 units and a productivity of 100 units per hour.

- $c i$ : low (0.02 monetary units/unit-period) and high (1 monetary units/unit-period).

- $\quad c r: 300$ (lost demand cost, per unit)

- Four patterns of product demand were considered: (1) constant with some large randomly generated peaks; (2) constant; (3) seasonal pattern with one peak and one valley; (4) seasonal pattern with two peaks. For seasonal patterns, maximum demand/minimum demand $=1.5$. Total required quantity was set close $( \pm 5 \%)$ to total capacity. For all patterns, a random noise of $\pm 5 \%$ was included for each week to generate different instances. An example of the four patterns can be seen in Figure 2 .

- To test the model with large instances, 100 workers are considered (the size of the model, which with one product only depends on the number of workers, remains unchanged and corresponds to 14,795 variables -most of them real-, and 19,741 constraints).

- Three cases are considered for the balance of the WTA of workers at the beginning of the planning horizon $\left(S_{\mathrm{w} 0}\right)$ :

- Case 1 (workers owe many hours): $80 \%$ of values $\in \mathrm{U}\left[0.9 \mathrm{~S}^{-}, 0.7 \mathrm{~S}^{-}\right]$and $20 \%$ of values $\in \mathrm{U}\left[\mathrm{S}^{-}, \mathrm{S}^{+}\right]$(randomly generated)

- Case 2 (company owe many hours): $80 \%$ of values $\in \mathrm{U}\left[0.7 \mathrm{~S}^{+}, 0.9 \mathrm{~S}^{+}\right]$and $20 \%$ of values $\in \mathrm{U}\left[\mathrm{S}^{-}, \mathrm{S}^{+}\right]$(randomly generated)

- Case 3 (balanced case): $80 \%$ of values $\in U$ [0.1S, $\left.0.1 \mathrm{~S}^{+}\right]$and $20 \%$ of values $\in \mathrm{U}\left[\mathrm{S}^{-}, \mathrm{S}^{+}\right]$(randomly generated)

\section{PARAMETERS}

- Five cases are considered for the WTA bounds $\left[\mathrm{S}^{-}, \mathrm{S}^{+}\right]$: $[-50,50],[-100,500],[-500$, $100],[-200,200],[-500,500]$.

- $h^{-}, h, h^{+}$and $h^{++}: 4,40,50$ and 60

- $u_{w}$ and $\hat{u}_{w}$ : (1) 100 and 200 hours; (2) 500 and 500 hours. 
- Three cases for the final global WTA balance $\left(w t a^{-}, w t a^{+}\right):(0,0)$ globally balanced, $\left(-S^{-} \cdot|W| / 2, S^{+} \cdot|W| / 2\right)$ half balanced, $\left(-S^{-} \cdot|W|, S^{+} \cdot|W|\right)$ free.

- $\alpha=40$ (cost of one hour of overtime, per worker)

- $\beta=30$ (cost of one hour of overaccount, per worker)

- $\lambda_{1}, \lambda_{2}$ and $\lambda_{3:} 1,0.5$ and 0.5 .

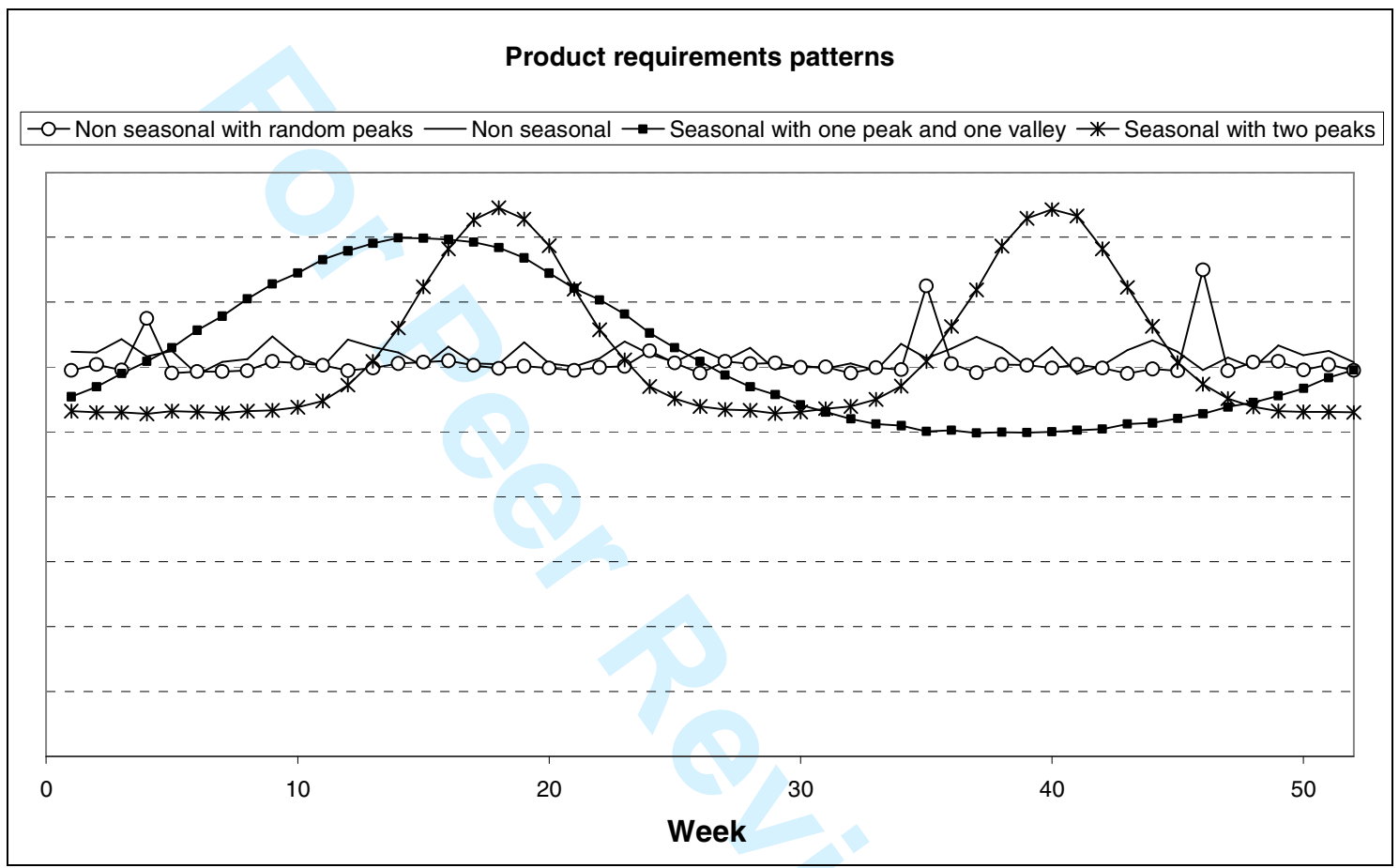

Figure 2. Product requirement patterns

For each one of the 720 combinations that are obtained with these data and parameters, ten instances were solved, giving a total amount of 7,200 instances. The experiment was performed using ILOG CPLEX 10.0 in a Pentium IV PC at $3.4 \mathrm{GHz}$ with $1 \mathrm{~Gb}$ of RAM. Absolute and relative MIP gap tolerances were set to 1E-06 and 1E-04.

The model was solved to optimality for most instances (98.3\%). There were only few instances whose solution optimality was not proven because the computer ran out of memory (1.69\%). Even though most of the instances with a not proven optimal solution require the global final WTA balance to be equal to zero (i.e. globally balanced), if only these kind of instances are analysed it can be seen that most of them (95.04\%) are solved to optimality. Table 1 sum up these results.

On the other hand, note that a feasible solution was obtained for the 7,200 instances. Furthermore, for the set of instances giving an out of memory (122 instances), the maximum difference between the obtained solution and the optimal one (the gap, 
computed as "100·(z-Best_Bound)/z", being $\mathrm{z}$ the value of the objective function of the obtained solution and the Best-bound the minimum bound among the bounds of the nodes that are opened when the execution of CPLEX is stopped) is always very small. The minimum, the average and the maximum gap of these instances' solution is equal to $0.01 \%, 0.47 \%$ and $3.82 \%$, respectively. Hence, in the worst case the difference between the obtained solution and the optimal one would not be greater than $3.82 \%$ and, on average, would not be greater than $0.47 \%$. Thus, it can be concluded that even in the few cases in which the model cannot be solved due to a lack of memory, the obtained solution is of very good quality.

\section{[INSERT TABLE 1: RESULTS OF THE COMPUTATIONAL EXPERIMENT]}

On the other hand, most instances are solved in very short times. Table 2 gives, for each group of instances (those with a proven optimal solution and those that caused an out of memory), the minimum computing time, the average computing time and the maximum computing time. For most cases computing times are quite short, considering the kind of problem being solved. Thus, it can be concluded that the proposed model can be solved efficiently.

\section{[INSERT TABLE 2: COMPUTING TIMES (IN SECONDS)]}

The 7200 instances can be divided into 24 groups of 300 instances each having the same type of data (same inventory holding cost, same pattern of product requirements and same type of workers' WTA balance at the beginning of the planning horizon). Hence, the cost of the solution (a part of the objective function) of the different instances is only comparable within a group, but not between instances belonging to different data groups, unless another (homogeneous) indicator is considered.

For each one of the 24 groups, the 300 instances (whose differences are due to differences in the WTA scheme configuration) were sorted according to the cost of the obtained solution and, for each instance, a relative cost saving was computed as the difference between the cost of the solution of the worst instance and the cost of the solution of the given instance, divided by the first one. This new homogenous indicator allowed us to compare instances belonging to different groups and to evaluate the influence of the WTA scheme configuration on the solution cost. As expected, the more flexible is the WTA scheme, the better is the solution (as cost is concerned). As an example, Figures 3 and 4 show the Box Plot of the cost saving for each value of WTA bounds and the final global balance, respectively, for instances with seasonal requirements with two peaks, balanced initial situation (WTA balances close to zero) and high inventory holding cost. In both figures, each box stretches from the lower 
hinge (defined as the 25th percentile) to the upper hinge (the 75th percentile) and therefore contains the middle half of the scores in the distribution. The length of the box is the interquartile range (IQR); Values more than three IQR's from the end of a box are labelled as extreme (*), and values more than 1.5 IQR's but less than 3 IQR's from the end of the box are labelled as outliers $(\mathrm{O})$. The median is shown as a line across the box. As expected, in Figure 3 it can be clearly seen that schemes with small WTA bounds (i.e., schemes with quite a limited flexibility, such as the one with a lower and an upper bound of -50 and +50 hours, respectively) do not allow for large cost savings. Figure 4 shows that, when the final WTA must be globally balanced, it is less likely to obtain large cost savings, specially compared to the other two alternatives (half balanced and free). Again, this can be explained in relation to the scheme flexibility (when the final WTA must be globally balanced the scheme becomes less flexible than when it is not necessary to finish with a globally balanced WTA). The more flexible is the system, the better capacity can be adapted to the requirements and the larger is the reduction in costs.

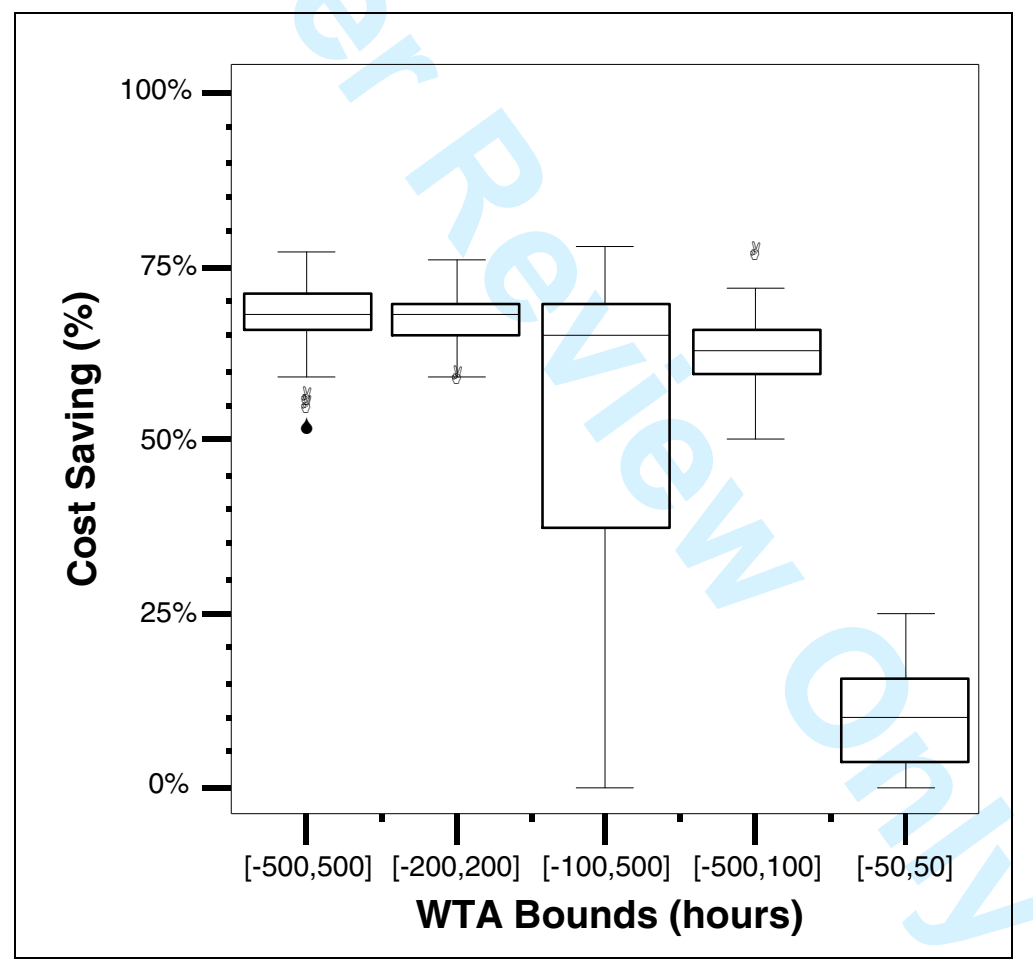

Figure 3. Cost savings for instances with "Seasonal requirements with two peaks, balanced initial situation (WTA balances close to zero), high inventory holding cost”, by WTA bounds (300 instances) 


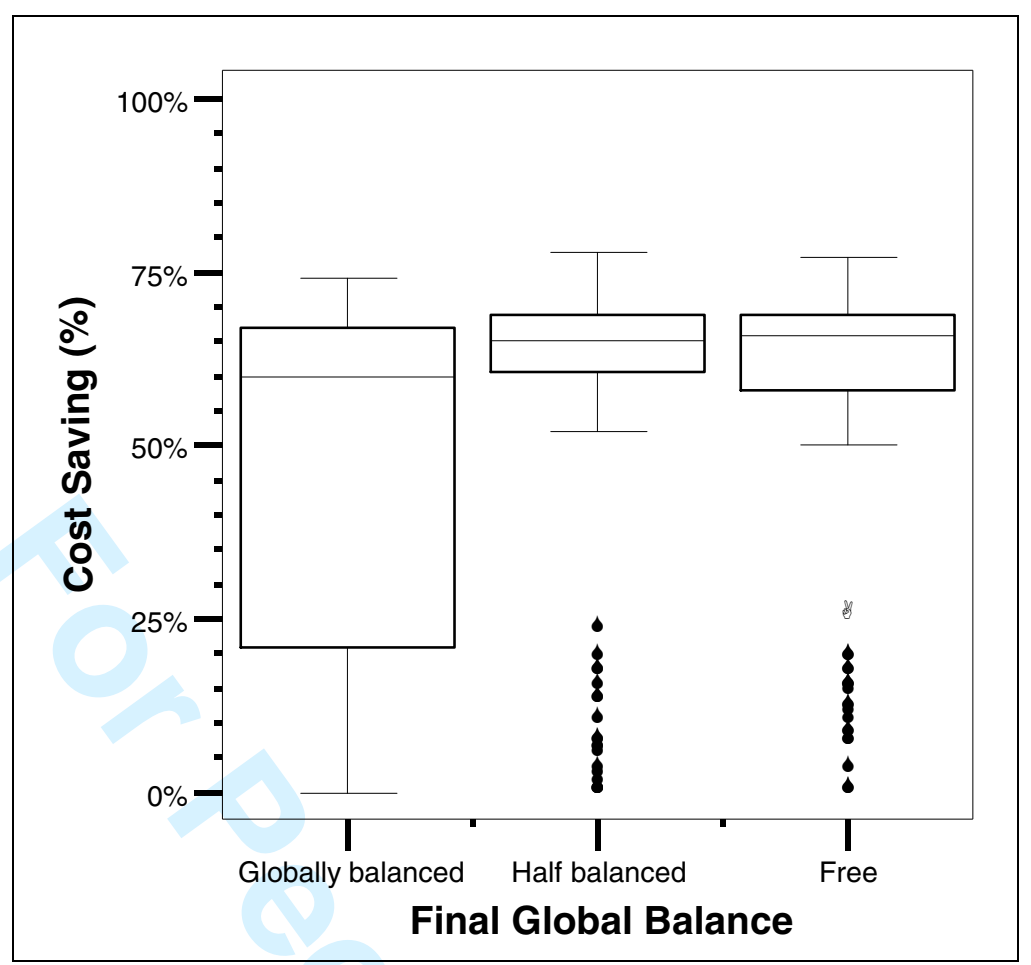

Figure 4. Cost savings for instances with "Seasonal requirements with two peaks, balanced initial situation (WTA balances close to zero), high inventory holding cost”, by final global WTA balance (300 instances)

When a company wants to adopt a WTA scheme it should evaluate different configurations (i.e., combinations of the WTA parameters) in order to base the negotiation of the characteristics of the WTA scheme on quantitative information. Thus, the model needs to be solved once for each configuration. Note that this would be perfectly possible, given the efficiency of the planning model.

Finally, Figures 5 and 6 show the detailed optimal solution for a specific instance with seasonal requirements with one peak and one valley, balanced initial situation (WTA balances close to zero), low inventory holding cost, WTA Bounds $[-200,200], u=100$ hours, $\hat{u}_{w}=200$ hours and final WTA globally balanced. Figure 5 shows how, thanks to the flexibility provided by the WTA and the possibility of having inventory, production is perfectly adapted to requirements. For example, it can be seen that before the block of holiday weeks (production is stopped), the production is increased (more working hours are planned) and enough inventory to meet requirements is created. In Figure 6, the evolution of the value of the WTA balance of each worker is depicted, which of course is in line with the evolution of production. Note that since most workers begin with a WTA balance close to 0 , there is a high number of lines (about 85) in the middle part of the figure, corresponding to the evolution of these 85 workers' WTA balance, that looks like a shaded area. In this figure it can be also seen that there are some underaccount hours caused by workers starting with a balance close to the WTA lower bound. In some weeks, whilst the WTA balance of most workers goes down, the WTA balance of those workers remains constant and equal to the WTA lower bound. 


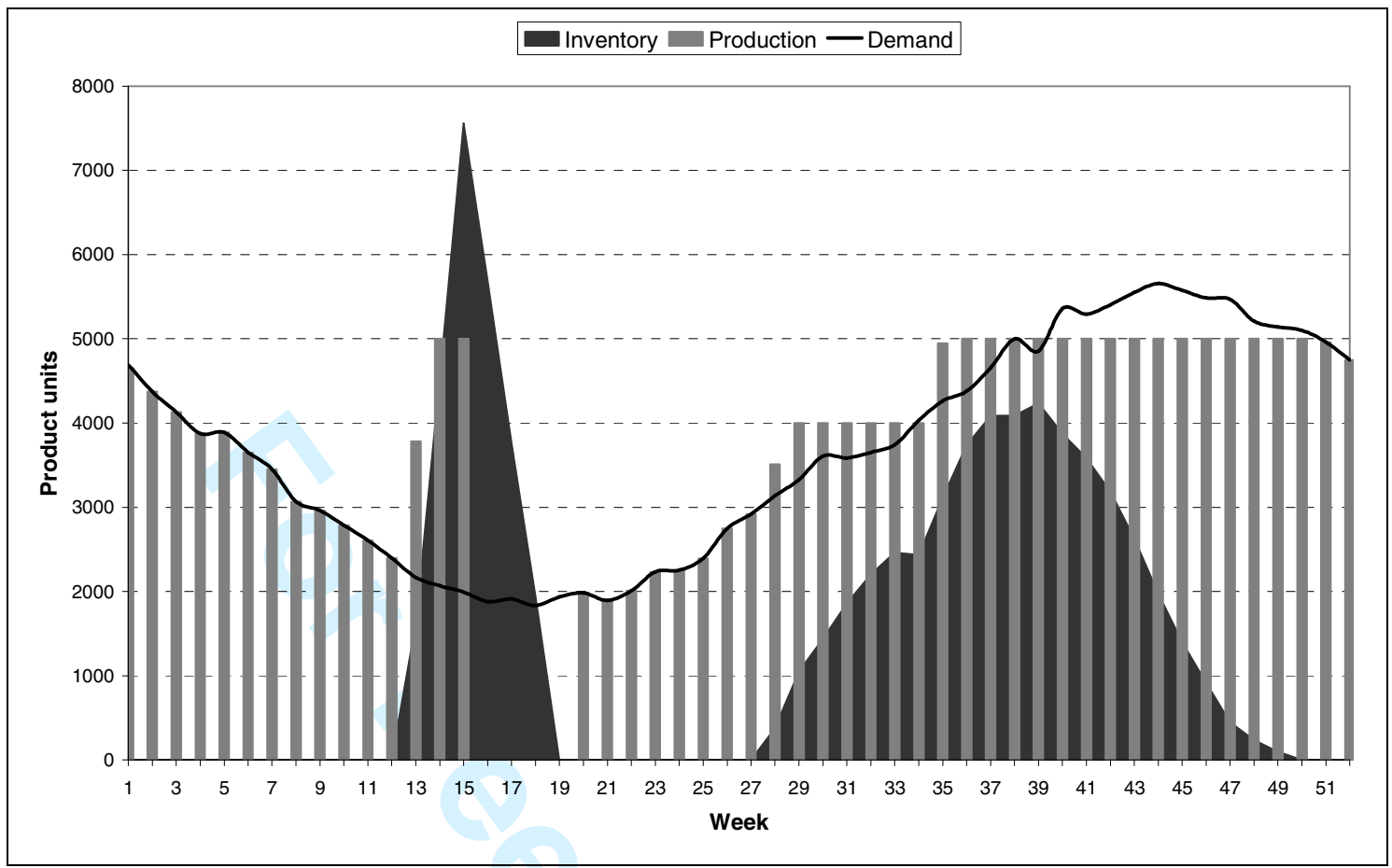

Figure 5. Required quantity, production and inventory for an instance with seasonal requirements with one peak and one valley, balanced initial situation (WTA balances close to zero), low inventory holding cost, WTA Bounds [-200,200], $u_{w}=100, \hat{u}_{w}=200$ and final WTA globally balanced

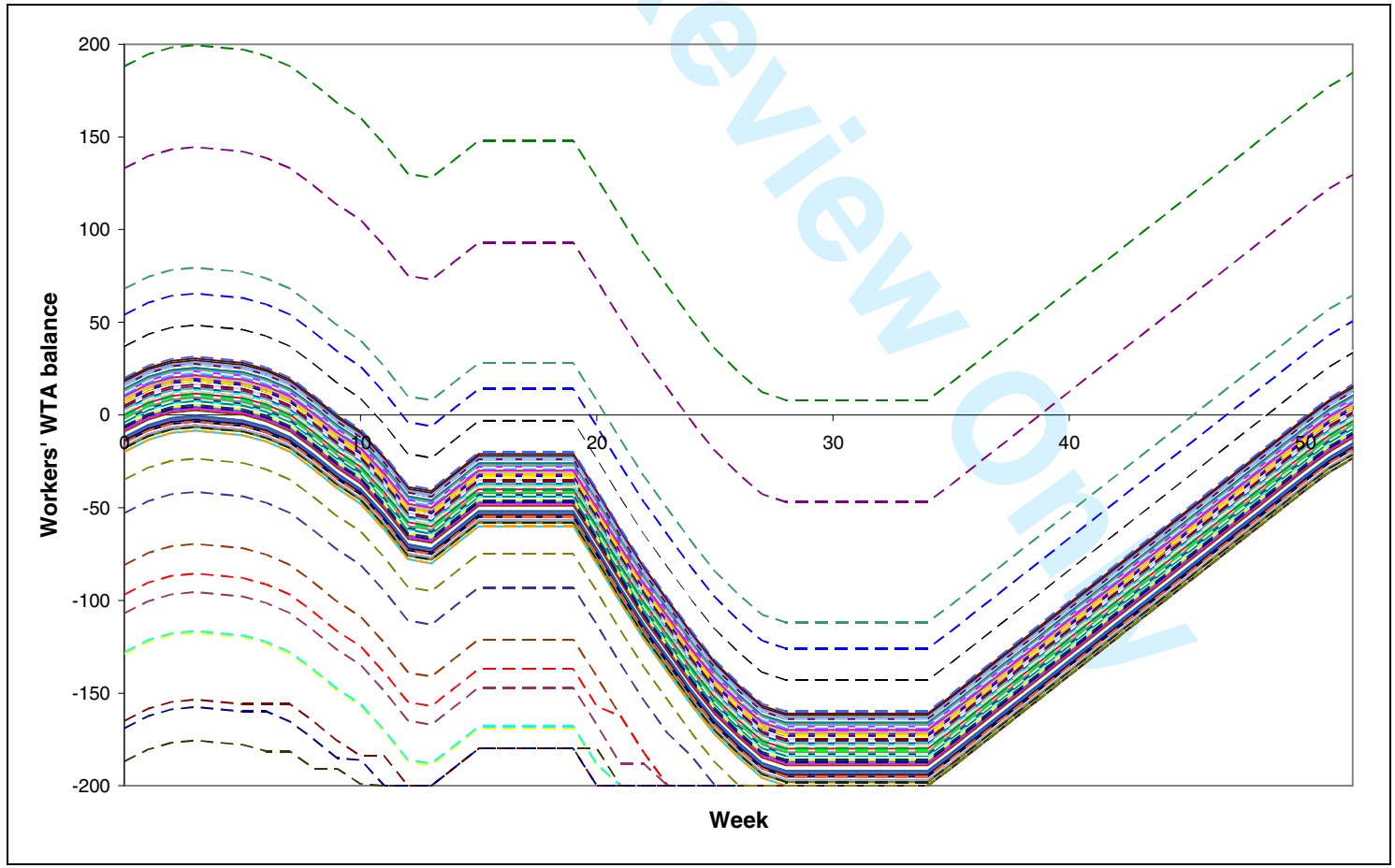

Figure 6. Example of workers' WTA balances for a solution of an instance with seasonal requirements with one peak and one valley, balanced initial situation (WTA balances close to zero), low inventory holding cost, WTA Bounds $[-200,200], u_{w}=100, \hat{u}_{w}=200$ and final WTA globally balanced 


\subsection{Experiment 2}

To check whether the number of products significantly affects the performance of the model or not, an additional experiment was run. In this second experiment, the number of products is varied from 1 to 50, which can be considered a sufficiently large quantity for aggregate planning. Instead of considering again all the possible data and parameters combinations, a configuration that had given a long average solving time in the first experiment was taken, and 75 instances were generated for each quantity of products, giving a total amount of 375 instances.

The selected combination of data and parameters corresponds to a low inventory holding cost (0.02 monetary units/unit-period), a seasonal demand with one peak and one valley, a balanced initial situation (case 3), a WTA bounded from -500 to +500 , an upper bound of 500 hours for the overtime and the overtime plus overaccount hours and a globally balanced final situation.

75 demand instances were generated for the 1 product case. For each one of them, the demand values, for each period, were randomly distributed between the products for generating the 75 instances for 5, 10, 20 and 50 products.

As expected, solving times increase with the number of products. Nevertheless, an optimal or near-optimal solution was always obtained in short times (considering the kind of problem being solved). Specifically, for the instances with a non-proven optimal solution, the average and maximum gap is equal to $0.02 \%$ and $0.64 \%$, respectively. Table 3 sums up the results of this second experiment. For each number of products examined it can be seen, besides the size of the model (number of variables and number of constraints), the minimum, the maximum and the average computing times obtained when solving the 75 instances.

\section{[INSERT TABLE 3: RESULTS OF THE SECOND COMPUTATIONAL EXPERIMENT. SOLVING TIMES (IN SECONDS) BY NUMBER OF PRODUCTS]}

Overall, it can be concluded that the model can be solved to optimality in very short times for most cases, becoming a very useful management tool. 


\section{Conclusions and further research}

In this paper, the problem of planning production, inventory levels, working time and temporary closures when working time accounts are used is stated and a mixed integer linear programming model is proposed to solve it. A computational study shows that, for instances of realistic size (a large number of workers and products), the model can be solved in short computing times. Therefore the proposed model can be used not only as a management tool but also in the bargaining process when different WTA scheme configurations are considered.

Of course the proposed model can be used to update the plan at any time. However, when a flexible working time scheme is applied it must be taken into account that, for the sake of workers' well-being, is desirable that the updated plan is as similar as possible to the previous one. For doing so, some modifications should be done to the model. Our future research includes designing and testing this kind of model.

Besides the previous idea and dealing with other versions of the problem, such as the cases in which demand can be served with delay (a backlog situation), the main prospects of future research include dealing with stochastic demand and incorporating WTA in aggregated planning models that integrate the diverse functional areas of a firm.

\section{Acknowledgements}

Supported by the Spanish MCyT projects DPI2004-05797 and DPI2007-61588, cofinanced by FEDER. The authors are grateful to Alberto García-Villoria for his help in performing the computational experiments. The authors are also grateful to the two anonymous referees who provided helpful comments on this paper.

\section{References}

Berg, P.; Appelbaum, E; Bailey, T.; Kalleberg, A.L. (2004). Contesting time: international comparisons of employee control of working time. Industrial \& Labor Relations Review, 57, 331-349.

Corominas, A.; Lusa, A.; Pastor, R. (2002). Using MILP to plan annualised working hours. Journal of the Operational Research Society, 53, 1101-1108.

Corominas, A.; Lusa, A.; Pastor, R. (2004). Characteristics and classification of the annualised working hours planning problems. International Journal of Services Technology and Management, 5, 435-447. 
Corominas, A.; Olivella, J.; Pastor, R. (2006). Capacity planning with working time accounts in services. Working paper IOC-DT-P-2006-27 (http://hdl.handle.net/2117/529).

Dellaert, N.; Jeunet, J. (2003). Controlling multi-level production in a rolling-schedule environment. International Journal of Production Economics, 85, 113-121.

Dribbusch, H. (2004). Agreements on cost-cutting and job security signed at Volkswagen. EIROnline, European Industrial Relations Observatory. http://www.eurofound.europa.eu/eiro/2004/11/feature/de0411203f.htm (Accessed 22-12005).

Haipeter, T.; Lehndorff, S. (2005). Decentralised bargaining of working time in the German automotive industry. Industrial Relations Journal, 36, 140-156.

Hung, R. (1999). Scheduling a workforce under annualized hours. International Journal of Production Research, 37, 2419-2427.

Lehndorff, S. (1999). New working time systems, work organisation and re-distribution of work. Düsseldorf, Institut Arbeit und Technik Abteilung Arbeitsmarkt: 89.

Lehndorff, S. (2000). Working time and operationg hours in the european automotive industry. Düsseldorf, Institut Arbeit und Technik Abteilung Arbeitsmarkt.

Lusa, A.; Corominas, A.; Pastor, R. (2008). An exact procedure to plan holidays and working time under annualised hours considering cross-trained workers with different efficiencies. International Journal of Production Research, 46, 2123-2142.

Owen, J. (1977). Flexitime: Some Problems and Solutions. Manufacturing and Labor Relations Review 30, 152-160.

Pastor, R..; Olivella, J. (2008). Selecting and adapting weekly work schedules with working time accounts: A case of a retail clothing chain. European Journal of Operational Research 184, 1-12.

Seifert, H.; Massa-Wirth, H. (2005). Pacts for employment and competitiveness in Germany. Industrial Relations Journal, 36, 217-240. 
Table 1. Results of the computational experiment

\begin{tabular}{|l|c|c|}
\hline & $\begin{array}{c}\text { All instances } \\
(7200)\end{array}$ & $\begin{array}{c}\text { Instances with final } \\
\text { WTA globally balanced } \\
(2400)\end{array}$ \\
\hline Optimal & $7078(98.3 \%)$ & $2281(95.04 \%)$ \\
\hline Feasible (Out of memory) & $122(1.69 \%)$ & $119(4.96 \%)$ \\
\hline
\end{tabular}


Table 2. Computing times (in seconds)

\begin{tabular}{|l|c|c|c|}
\hline & $\begin{array}{c}\text { Min } \\
\text { time }\end{array}$ & $\begin{array}{c}\text { Average } \\
\text { time }\end{array}$ & $\begin{array}{c}\text { Max } \\
\text { time }\end{array}$ \\
\hline $\begin{array}{l}\text { Instances with a proven optimal solution (98.3\% of } \\
\text { instances: } 7078 \text { instances) }\end{array}$ & 0.57 & 39 & 11501 \\
\hline $\begin{array}{l}\text { Instances with a not proven optimal solution (out of } \\
\text { memory; 1.69\% of instances: 122 instances) }\end{array}$ & 429 & 2408 & 25702 \\
\hline
\end{tabular}


Table 3. Results of the second computational experiment. Solving times (in seconds) by number of products

\begin{tabular}{|c|c|c|c|c|c|}
\hline Num. products & Num. var. & Num. constr. & $\begin{array}{c}\text { Min } \\
\text { time }\end{array}$ & $\begin{array}{c}\text { Average } \\
\text { time }\end{array}$ & Max time \\
\hline 1 & 14795 & 19741 & 16 & 1734 & 4213 \\
\hline 5 & 15403 & 20141 & 31 & 2375 & 6887 \\
\hline 10 & 16163 & 20641 & 23 & 2996 & 7713 \\
\hline 20 & 17683 & 21641 & 26 & 3163 & 6390 \\
\hline 50 & 22243 & 24641 & 45 & 4337 & 9189 \\
\hline
\end{tabular}




\section{FIGURE CAPTIONS}

- Figure 1. Conditions of the WTA scheme

- Figure 2. Product requirement patterns

- Figure 3. Cost savings for instances with "Seasonal requirements with two peaks, balanced initial situation (WTA balances close to zero), high inventory holding cost", by WTA bounds (300 instances)

- Figure 4. Cost savings for instances with "Seasonal requirements with two peaks, balanced initial situation (WTA balances close to zero), high inventory holding cost", by final global WTA balance (300 instances)

- Figure 5. Required quantity, production and inventory for an instance with seasonal requirements with one peak and one valley, balanced initial situation (WTA balances close to zero), low inventory holding cost, WTA Bounds [-200,200] and final WTA globally balanced

- Figure 6. Example of workers' WTA balances for a solution of an instance with seasonal requirements with one peak and one valley, balanced initial situation (WTA balances close to zero), low inventory holding cost, WTA Bounds [-200,200] and final WTA globally balanced 